\title{
Maternal educational status at birth, maternal educational advancement, and neurocognitive outcomes at age 10 years among children born extremely preterm
}

\author{
Robert M. Joseph ${ }^{1}$, Thomas M. O'Shea ${ }^{2}$, Elizabeth N. Allred ${ }^{3}$, Tim Heeren ${ }^{4}$ and Karl K. Kuban ${ }^{5}$ \\ for the ELGAN Study Investigators ${ }^{6}$
}

BACKGROUND: To determine if a key marker of socioeconomic status, maternal education, is associated with later neurocognitive and academic outcomes among children born extremely preterm (EP).

METHOD: Eight hundred and seventy-three children born at 23 to 27 weeks of gestation were assessed for cognitive and academic ability at age 10 years. With adjustments for gestational age (GA) and potential confounders, outcomes of children whose mothers had fewer years of education at the time of delivery and children whose mother advanced in education between birth and 10 years were examined.

RESULTS: Children of mothers in the lowest education stratum at birth were significantly more likely to score $\geq 2$ SDs below normative expectation on 17 of 18 tests administered. Children of mothers who advanced in education $(n=199)$ were at reduced risk for scoring $\geq 2$ SDs on 15 of 18 measures, but this reduction was statistically significant on only 2 of 18 measures.

CONCLUSION: Among EP children, socioeconomic disadvantage at birth, indexed by maternal education, is associated with significantly poorer neurocognitive and academic outcomes at 10 years of age, independently of GA. Maternal educational advancement during the child's first 10 years of life is associated with modestly improved neurocognitive outcomes.

$\mathbf{N}$ eurocognitive deficits and learning difficulties are the most common impairments among individuals born preterm $(1,2)$, and their severity increases with decreasing gestational age at birth (3-5). Lower household socioeconomic status (SES), itself a risk factor for prematurity $(6,7)$, is also associated with poorer cognitive outcomes among those born preterm (8-13). Markers of social advantage and disadvantage, such as household income and parental education, are understood as not only affecting neurocognitive outcomes directly but also via the multitude of pre- and and postnatal physical and psychosocial environmental factors with which they are associated (14-16).

Increased biological risk among infants born earlier than 28 weeks of gestation, and most vulnerable to medical complications and neurological damage, may limit the influence of environmental factors on developmental outcomes $(1,15,17-19)$. Thus, the extent to which the effects of social disadvantage generalize to children born extremely preterm is unclear (10). In addition, it is not known whether improvement in the family's socioeconomic circumstances during the child's first decade of life is associated with better cognitive outcomes of children born extremely preterm.

In the present study, we examined to what extent household SES at birth was associated, independently of gestational age, with neurocognitive and academic deficits at age 10 years in the prospectively followed Extremely Low Gestational Age Newborns (ELGAN) cohort of children born at 23 to 27 weeks of gestation. We focused primarily on maternal educational status as a proxy measure of SES (7), which was strongly associated with household income in the ELGAN cohort, as measured by eligibility for public (government-provided) health insurance (i.e., Medicaid) (20). We examined associations between maternal educational status at delivery and children's neurocognitive and academic outcomes at age 10 years, adjusting for weeks of gestational age as well as other possible confounders, including fetal growth restriction (11), maternal intelligence quotient (IQ) (21), and minority ethnic/ racial status (14). In addition, we assessed associations between advances in educational attainment, which occurred for a substantial proportion of mothers $(n=199)$ in our prospectively followed cohort, and children's 10-year outcomes.

\footnotetext{
${ }^{1}$ Department of Anatomy and Neurobiology, Boston University School of Medicine, Boston, Massachusetts; ${ }^{2}$ Department of Pediatrics, University of North Carolina, Chapel Hill, North Carolina; ${ }^{3}$ Department of Neurology, Boston Children's Hospital and Harvard Medical School, Boston, Massachusetts; ${ }^{4}$ Department of Biostatistics, Boston University School of Public Health, Boston, Massachusetts; ${ }^{5}$ Department of Pediatrics, Boston Medical Center, Boston, Massachusetts. Correspondence: Robert M. Joseph (rmjoseph@bu.edu)

${ }^{6}$ Members of the ELGAN Study Investigators are listed before References.

Received 24 July 2017; accepted 25 September 2017; advance online publication 22 November 2017. doi:10.1038/pr.2017.267
} 


\section{METHODS}

\section{Participants}

The ELGAN study is a multicenter observational study designed to identify characteristics and exposures associated with increased risk of structural and functional neurologic disorders in extremely preterm infants (22). During the years 2002-2004, women delivering before 28 weeks of gestation in 11 cities in 5 states were asked to enroll in the study. One thousand two hundred and forty-nine mothers of 1,506 infants consented to participate. Of the 1,198 children who survived to 10 years of age, 966 were actively recruited for follow-up (because of the availability of blood samples collected during their first postnatal month) and 889 (92\%) agreed to participate. Of these 889 children, 11 did not accompany the parent or caregiver during the follow-up visit, and 5 did not cooperate with the child assessment, leaving a final sample of 873 children. Procedures for this study were approved by the institutional review boards of the participating institutions.

\section{Maternal and Newborn Characteristics}

Maternal education, eligibility for public health insurance, age, marital status, and racial and ethnic identity were self-reported. To approximate the heritable component of child IQ, maternal IQ was assessed with the Kaufman Brief Intelligence Test-2 (KBIT-2) (23) nonverbal subscale at the 10 -year visit.

Gestational age (GA) estimates were based on a hierarchy of the quality of available information: dates of embryo retrieval or intrauterine insemination or fetal ultrasound before the 14th week (62\%) followed by fetal ultrasound at 14 or more weeks $(29 \%)$, last menstrual period without fetal ultrasound (7\%), and GA recorded in the neonatal intensive care unit $\log (1 \%)$. Fetal growth restriction was defined as birth weight $Z$-score below -2, i.e., $2 \mathrm{SDs}$ below the median weight of infants at the same GA in a referent sample not delivered for preeclampsia or fetal indications (22).

Supplementary Table S1 (online) compares the maternal and child characteristics of children who did and did not participate in the 10-year follow-up evaluation. From among the 1,198 children who survived to 10 years of age, those who did not participate $(n=309)$ were more likely to have indicators of social disadvantage, including lower maternal education and receipt of public health insurance, but did not differ from those who participated with respect to newborn characteristics, including sex, gestational age, and birth weight $Z$-score.

\section{Procedures at Age 10 years}

Test measures were selected to provide the most comprehensive information about neurocognitive and academic function in one 4-h testing session (including breaks) to maximize participation and data collection. The parent or caregiver completed questionnaires regarding the child's medical and neurological status.

\section{Sensorimotor Status at Age 10 years}

Severe gross motor dysfunction was defined as Level 5 (i.e., no selfmobility) on the Gross Motor Function Classification System (24). A child was considered to have severe visual impairment if the parent reported uncorrectable functional blindness in both eyes. No participant had a significant, uncorrected hearing impairment.

\section{Neurocognitive and Academic Ability at Age 10 years}

Neurocognitive and academic achievement assessments were based on well-validated tests with recently standardized scores allowing comparison to US population norms.

General cognitive ability. General cognitive ability (or IQ) was assessed with the School-Age Differential Ability Scales-II (DAS-II) (25) Verbal and Nonverbal Reasoning Scales. The DAS-II has several advantages for characterizing the wide range of IQ in a preterm sample, including more sensitive basal items than other IQ scales and extended standard scores (down to 31 ).
Language ability. Expressive and receptive language skills were evaluated with the Oral and Written Language Scales (26), which assess semantic, morphological, syntactic, and pragmatic production and comprehension of elaborated sentences.

Executive function. Attention and executive function were assessed with the DAS-II and the NEPSY-II (27). DAS-II Recall of Digits Backward and Recall of Sequential Order measured verbal working memory. NEPSY-II Auditory Attention and Auditory Response Set evaluated auditory attention, set switching, and inhibition. NEPSY-II Inhibition Inhibition and Inhibition Switching assessed simple inhibition and inhibition in the context of set shifting, respectively. NEPSY-II Animal Sorting measured concept generation and mental flexibility.

Speed of processing. Speed of processing was assessed with NEPSYII Inhibition Naming, a baseline measure of processing speed with no inhibitory component.

Visual perception. Visual perception was assessed with NEPSY-II Arrows, which measures perception of line orientation, and Geometric Puzzles, a measure of mental rotation of complex visual-spatial figures.

Visual-motor function. Visual fine motor function was measured with NEPSY-II Visuomotor Precision.

Academic achievement. The Wechsler Individual Achievement Test-III (WIAT-III) (28) Word Reading, Pseudoword Decoding, and Spelling subtests were used to assess proficiency in word recognition, decoding, and spelling, respectively. WIAT-III Numerical Operations was used to assess math-related computational skills.

\section{Data Analyses}

We evaluated the null hypothesis that maternal educational level at the time of delivery and maternal educational advancement (any time after delivery) are not associated with poorer neurocognitive or academic function among ELGANs assessed at 10 years of age. To compare the test performance of ELGANs to normative expectation, we converted children's test scores to $Z$-scores using the normative means and SDs for each subtest.

To examine associations among SES-related maternal variables and newborn characteristics $(P<0.10)$, we used Fisher's exact tests, except in the case of maternal education and IQ, for which a Pearson's $\chi^{2}$ test was used because of the large number of cells. To examine associations between maternal education at delivery and child neurocognitive and academic outcomes at age 10 years, we used multinomial logistic regression to compare the children of mothers who had $\leq 12$ years (high school or less) and $>12$ but $<16$ years (some college or secondary school education) to those of mothers with $\geq 16$ years (bachelor's degree or higher) of education, the referent group. We estimated the odds ratios (ORs) of having a test score 2 or more SDs and between 1 and 2 SDs below the normative mean, adjusting for minority ethnic/racial status, maternal IQ (KBIT-2 Z-score $\leq-1$ ), male sex, GA (23-24 and 25-26 weeks), and birth weight $Z$-score $<-1$, while also accounting for the correlations between children from the same pregnancy.

To examine the associations between mothers' educational advancement and children's neurocognitive outcomes, we added a term for advance of maternal education after the child's birth to the model described above. The ORs for this term permitted us to assess whether a mother's receipt of additional education reduced the likelihood of cognitive and academic deficits for her child.

We did not adjust for eligibility for public health insurance in the models described above because, as an alternative proxy measure of SES, it was strongly associated with maternal educational status $(P \leq 0.0005)$. However, we did conduct supplemental analyses to 
Table 1. Sample characteristics by maternal education and eligibility for public health insurance

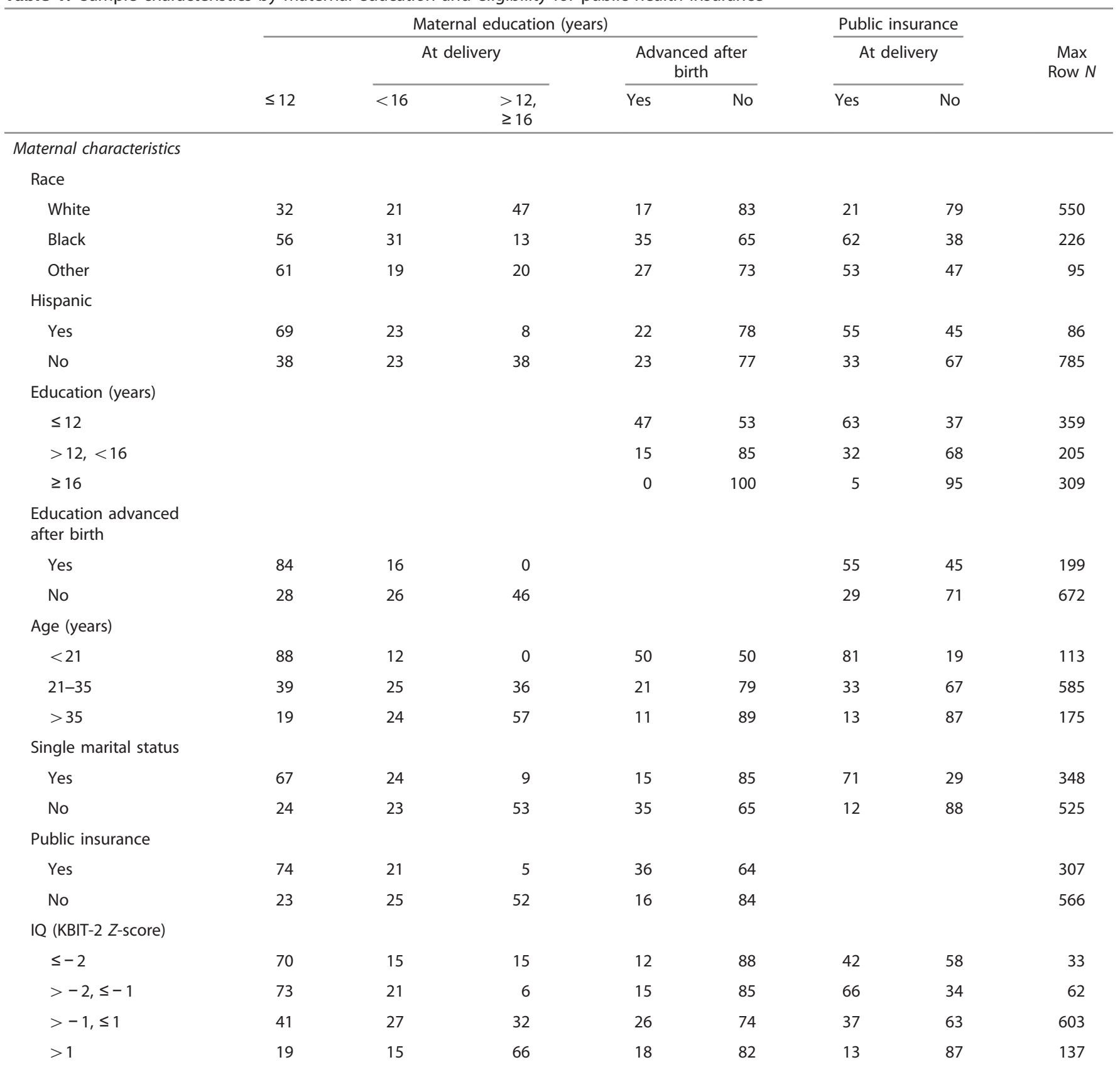

Newborn characteristics

Sex

Male

Female

Gestational age (weeks)

\section{3-24 \\ 25-26}

27

Birth weight (g)

$40 \quad 22$

42

43

44

37

43
22

25
38

33
22

24
78

76

67

62

64

64

67

81

39

30
22 


\begin{tabular}{|c|c|c|c|c|c|c|c|c|}
\hline & \multicolumn{5}{|c|}{ Maternal education (years) } & \multirow{2}{*}{\multicolumn{2}{|c|}{$\frac{\text { Public insurance }}{\text { At delivery }}$}} & \multirow[b]{2}{*}{$\begin{array}{l}\text { Max } \\
\text { Row } \Lambda\end{array}$} \\
\hline & $\leq 12$ & \multicolumn{2}{|c|}{ At delivery } & \multicolumn{2}{|c|}{$\begin{array}{l}\text { Advanced after } \\
\text { birth }\end{array}$} & & & \\
\hline $751-1,000$ & 44 & 21 & 34 & 25 & 75 & 37 & 63 & 378 \\
\hline$>1,000$ & 30 & 23 & 47 & 20 & 80 & 24 & 76 & 172 \\
\hline$<-2$ & 45 & 14 & 41 & 29 & 71 & 31 & 69 & 51 \\
\hline$\geq-2,<-1$ & 46 & 28 & 27 & 24 & 76 & 41 & 59 & 116 \\
\hline$\geq-1$ & 40 & 24 & 36 & 22 & 78 & 34 & 66 & 706 \\
\hline Maximum column $N$ & 359 & 205 & 309 & 199 & 672 & 307 & 566 & 873 \\
\hline
\end{tabular}

Row percents. Maximum $N=873$.

assess the relationship between household eligibility for public insurance (i.e., Medicaid) at delivery with children's 10-year outcomes. We did not conduct analyses of the effects of change in public health-care insurance status because the expansion of Medicaid eligibility under the US Affordable Care Act in 2010 made it an uninterpretable measure of change in household income.

\section{RESULTS}

\section{Sample Characteristics}

Of the 873 children in the final sample, $21 \%(n=180)$ were born at 23-24 weeks GA, 45\% $(n=395)$ at 25-26 weeks GA, and $34 \%(n=298)$ at 27 weeks GA (Table 1). Demographic characteristics associated with delivery before 27 weeks gestation were maternal education $\leq 12$ years $(P=0.007)$ and mother's minority ethnic/racial identification $(P=0.087)$. Boys were more likely than girls to be born at 23-24 weeks GA $(P=0.045)$. Severely growth-restricted (birth weight $Z$ score $<-2)$ infants were the least likely to be born at 2324 weeks GA $(P \leq 0.001)(5)$.

Of the 873 participants, 17 (1.9\%) had severe motor impairment, 7 (0.8\%) functional blindness, and $2(0.2 \%)$ had both severe motor impairment and functional blindness. Participants not able to obtain a basal score on any given test because of severe cognitive impairment were assigned a floor score for that test. Of the 26 children with severe motor or visual impairment, 17 did not achieve basal scores on any test, and 2 obtained basal scores on some but not all measures. Of children without severe motor or visual impairment, 12 did not achieve basal scores on any test, and 9 on only some tests. In sum, a total of 29 children were assigned floor scores on all tests, and 11 were assigned floor scores on some tests.

Maternal educational status was distributed as follows: Mothers with $\leq 12$ years of education were more likely $(63 \%)$ to be eligible for public health insurance than mothers who had $>12$, but $<16$ years $(32 \%)$ and mothers who had $\geq 16$ years $(5 \%)$ of education $(P \leq 0.0005)$. Lower maternal education was also associated with identification as non-white or Hispanic $(P \leq 0.0005)$, lower maternal age $(P \leq 0.0005)$ and single marital status at delivery $(P \leq 0.0005)$, lower maternal IQ $(P \leq 0.0005)$, lower gestational age $(P=0.007)$, and lower birth weight $(P=0.002)$. Of 873 children, 307 (35\%) were born to mothers who were eligible for public health insurance, which was associated with the same maternal demographic and child neonatal factors as was low maternal education.

Between birth and the 10-year follow-up, the mothers of 199 children (23\%) advanced in educational status, the large majority of whom shifted from having a high school degree or less to some college or secondary school education $(n=168)$ (see Table 1). Mothers who advanced in education were more likely to be non-white $(P \leq 0.0005)$, under 21 years of age $(P \leq 0.0005)$, married $(P \leq 0.0005)$, and eligible for public health insurance $(P \leq 0.0005)$ when their child was born than mothers who did not advance in education. The children of mothers who did and did not advance in education were similar in newborn characteristics (e.g., GA and fetal growth restriction).

\section{Neurocognitive and Academic Achievement Test Scores by Maternal Education at Delivery}

Box-and-whisker plots show the unadjusted medians and distributions of $Z$-scores for each test for each level of maternal education (Figure 1). The distributions of scores of children of mothers who had $\leq 12$ years or $>12$ but $<16$ years of education were shifted downward on all measures relative to children whose mother had $\geq 16$ years. Children whose mother had $\geq 16$ years of education had distributions of scores that were similar to the normative sample on several measures, including DAS-II verbal and nonverbal IQ, Oral and Written Language Scales receptive and expressive language, and all WIAT-III academic achievement tests, but had scores on measures of working memory and executive function, visual-perceptual skills, and fine motor function that were lower than normative expectation.

With adjustment for gestational age, birth weight $Z$-score, race, and maternal IQ, children whose mother had $\leq 12$ years of education were significantly more likely than those whose mothers had $\geq 16$ years of education to score 2 or more SDs below normative expectation on all tests except NEPSY-II Auditory Attention (Table 2 and Figure 2). These associations 

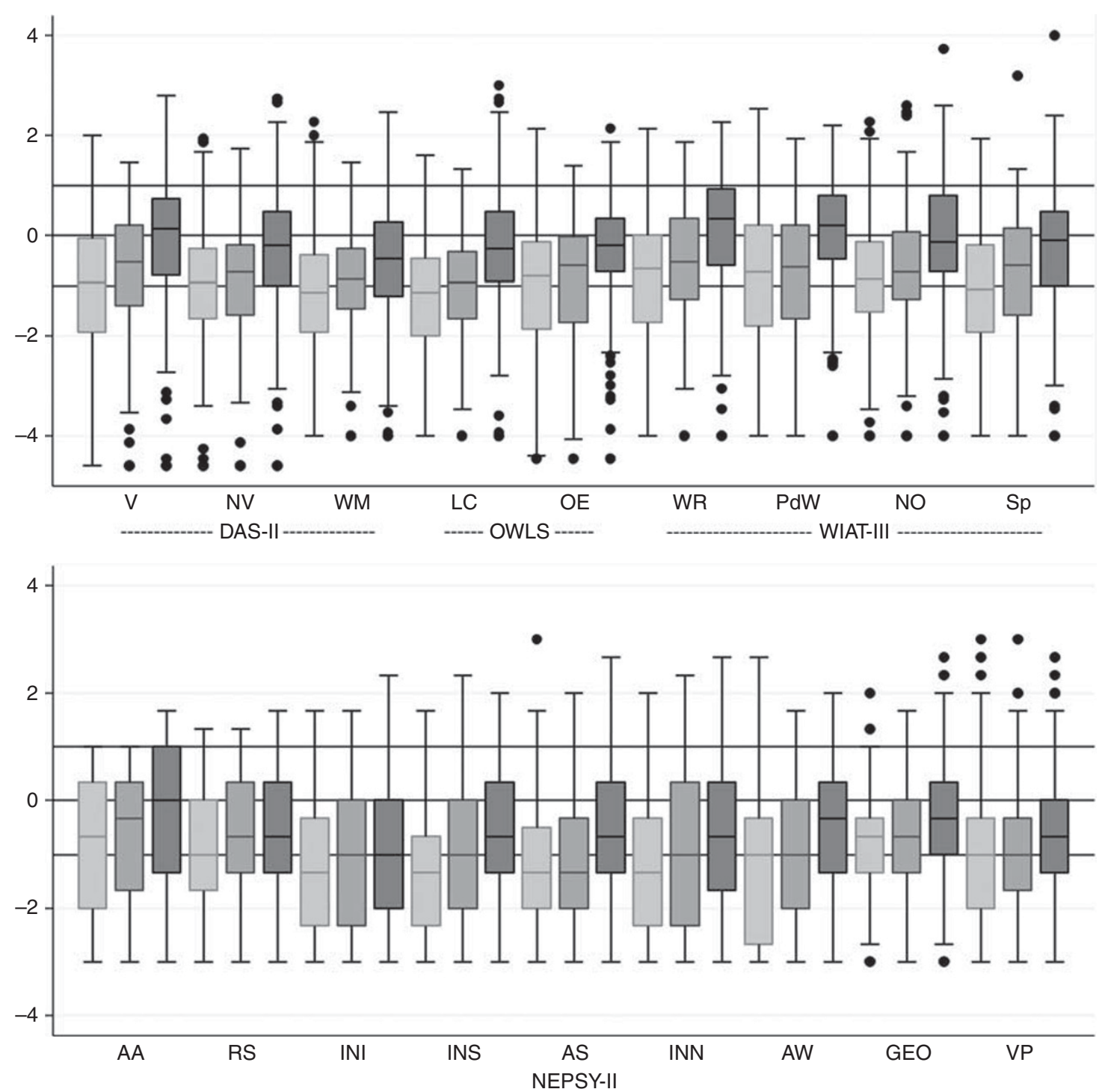

Figure 1. Box-and-whisker plots of neurocognitive and academic subtests by maternal education category. Z-scores were adjusted to population norms. Light gray bars indicate $\leq 12$ years education, medium gray bars indicate $>12$ but $<16$ years education, and dark gray bars indicate $\geq 16$ years education. The central line in the box indicates the median, and the top and bottom lines indicate the 75th centile and 25th centile, respectively. Maximum $N=873$. AA, auditory attention; AS, animal sorting; AW, arrows, GEO, geometric puzzles; INI, inhibition inhibition; INN, inhibition naming; INS, inhibition switching, LC, listening comprehension; NO, numerical operations; NV, nonverbal reasoning; OE, oral expression, $\mathrm{PdD}$, pseudoword decoding, RS, auditory response set; Sp, spelling; V, verbal, WM, working memory; WR, word reading.

were strongest for tests of verbal and nonverbal IQ, expressive language, inhibitory control, and mental flexibility (ORs from 2.5 to 3.6) as well as WIAT-III academic achievement measures (ORs from 3.2 to 3.9). Children of women with $\leq 12$ years of education also were more likely to score between 1 and 2 SDs below expectation on the majority of tests, including measures of verbal and nonverbal IQ, receptive and expressive language, working memory, inhibition, and mental flexibility, and all WIAT-III academic achievement measures.

Children whose mother had $>12$ but $<16$ years of education were also more likely than children of mothers who had $\geq 16$ years of education to score 2 or more SDs below normative expectation on the majority of tests administered, including measures of verbal and nonverbal IQ, expressive language, and executive control, and all measures of academic achievement. This group of children was more likely to score between 1 and 2 SDs below population norms on five tests, two of executive function and three of reading and math achievement.

Adjusted ORs demonstrate a clear pattern of increasing likelihood of lower test scores in association with decreasing maternal education (Table 2 and Figure 2). This pattern was apparent for all tests with the exception of NEPSY-II Auditory Attention and Animal Sorting, both measures of executive function, and NEPSY-II Visuomotor Precision, a measure of fine motor control. 
Table 2. Odds ratios (95\% confidence intervals) of $Z$-scores $\leq-2$ and $Z$-scores $>-2$ but $\leq-1$ for each neurocognitive, language, and academic achievement subtest at age 10 years associated with maternal education $\leq 12$ years or $>12$ but $<16$ years at the time the child was born

\begin{tabular}{|c|c|c|c|c|c|}
\hline \multirow[t]{3}{*}{ Subtest } & \multirow[t]{3}{*}{ Maternal education } & \multicolumn{4}{|c|}{ Odds ratio (95\% confidence interval) for a subtest Z-score } \\
\hline & & \multicolumn{2}{|c|}{ Education at birth } & \multicolumn{2}{|c|}{ Education at birth plus advanced after birth } \\
\hline & & $\leq-2$ & $>-2, \leq-1$ & $\leq-2$ & $>-2, \leq-1$ \\
\hline \multicolumn{6}{|l|}{ IQ } \\
\hline \multirow[t]{3}{*}{ DAS-II Verbal } & $\leq 12 \mathrm{yrs}$ at birth & $2.6(1.5,4.5)$ & $2.9(1.8,4.6)$ & $3.3(1.8,6.0)$ & $3.4(2.0,5.8)$ \\
\hline & $>12,<16$ yrs at birth & $1.8(0.99,3.3)$ & $1.6(0.9,2.8)$ & $2.0(1.1,3.6)$ & $1.7(0.9,2.9)$ \\
\hline & Advanced after birth & - & - & $0.6(0.3,1.02)$ & $0.7(0.4,1.2)$ \\
\hline DAS-II Nonverbal & $\leq 12$ yrs at birth & $2.6(1.5,4.6)$ & $2.0(1.3,3.1)$ & $2.7(1.4,5.1)$ & $1.9(1.2,3.1)$ \\
\hline \multirow[t]{2}{*}{ Reasoning } & $>12,<16$ yrs at birth & $2.0(1.1,3.9)$ & $1.6(0.98,2.5)$ & $2.1(1.1,4.0)$ & $1.5(0.9,2.5)$ \\
\hline & Advanced after birth & - & - & $0.8(0.5,1.4)$ & $1.1(0.7,1.8)$ \\
\hline \multicolumn{6}{|l|}{ Language } \\
\hline OWLS Listening & $\leq 12$ yrs at birth & $2.1(1.3,3.7)$ & $2.1(1.4,3.2)$ & $2.7(1.5,5.0)$ & $2.6(1.6,4.2)$ \\
\hline \multirow[t]{2}{*}{ Comprehension } & $>12,<16$ yrs at birth & $1.3(0.7,2.4)$ & $1.4(0.9,2.2)$ & $1.5(0.8,2.7)$ & $1.5(0.9,2.4)$ \\
\hline & Advanced after birth & - & - & $0.6(0.3,1.02)$ & $0.7(0.4,1.05)$ \\
\hline \multirow[t]{3}{*}{ OWLS Oral Expression } & $\leq 12$ yrs at birth & $3.6(2.1,6.1)$ & $2.1(1.3,3.3)$ & $4.1(2.2,7.7)$ & $2.7(1.6,4.4)$ \\
\hline & $>12,<16$ yrs at birth & $2.1(1.1,3.9)$ & $1.6(0.98,2.6)$ & $2.3(1.2,4.2)$ & $1.7(1.05 .2 .8)$ \\
\hline & Advanced after birth & - & - & $0.7(0.4,1.2)$ & $0.6(0.4,1.1)$ \\
\hline \multicolumn{6}{|l|}{ Academic achievement } \\
\hline \multirow[t]{3}{*}{ WIAT-III Word Reading } & $\leq 12$ yrs at birth & $4.3(2.2,8.5)$ & $2.3(1.4,3.9)$ & $4.5(2.1,9.5)$ & $2.9(1.6,5.1)$ \\
\hline & $>12,<16$ yrs at birth & $3.0(1.4,6.3)$ & $2.1(1.2,3.7)$ & $3.1(1.5,6.5)$ & $2.2(1.2,3.9)$ \\
\hline & Advanced after birth & - & - & $0.8(0.5,1.5)$ & $0.6(0.4,1.05)$ \\
\hline WIAT-III Pseudoword & $\leq 12$ yrs at birth & $3.5(1.9,6.3)$ & $2.3(1.4,3.9)$ & $3.8(1.9,7.2)$ & $2.5(1.4,4.3)$ \\
\hline \multirow[t]{2}{*}{ Decoding } & $>12,<16$ yrs at birth & $3.0(1.6,5.6)$ & $2.3(1.4,4.0)$ & $3.1(1.6,5.9)$ & $2.4(1.4,4.1)$ \\
\hline & Advanced after birth & - & - & $0.8(0.5,1.3)$ & $0.9(0.5,1.5)$ \\
\hline \multirow[t]{3}{*}{ WIAT-III Spelling } & $\leq 12$ yrs at birth & $3.5(1.8,6.9)$ & $1.8(1.03,3.0)$ & $3.4(1.6,7.2)$ & $2.0(1.1,3.5)$ \\
\hline & $>12,<16$ yrs at birth & $2.9(1.4,6.0)$ & $1.9(1.1,3.5)$ & $2.9(1.4,6.1)$ & $2.0(1.1,3.6)$ \\
\hline & Advanced after birth & - & - & $1.0(0.5,1.7)$ & $0.8(0.5,1.3)$ \\
\hline WIAT-III Numeric & $\leq 12$ yrs at birth & $4.5(2.5,8.0)$ & $2.9(1.8,4.5)$ & $5.2(2.7,9.8)$ & $3.5(2.2,5.8)$ \\
\hline \multirow[t]{2}{*}{ Operations } & $>12,<16$ yrs at birth & $3.0(1.5,5.8)$ & $2.1(1.3,3.4)$ & $3.2(1.6,6.2)$ & $2.2(1.4,3.7)$ \\
\hline & Advanced after birth & - & - & $0.7(0.4,1.2)$ & $0.7(0.4,1.1)$ \\
\hline
\end{tabular}




\begin{tabular}{|c|c|c|c|c|c|}
\hline \multirow[t]{3}{*}{ Subtest } & \multirow[t]{3}{*}{ Maternal education } & \multicolumn{4}{|c|}{ Odds ratio ( $95 \%$ confidence interval) for a subtest Z-score } \\
\hline & & \multicolumn{2}{|c|}{ Education at birth } & \multicolumn{2}{|c|}{ Education at birth plus advanced after birth } \\
\hline & & $\leq-2$ & $>-2, \leq-1$ & $\leq-2$ & $>-2, \leq-1$ \\
\hline \multicolumn{6}{|l|}{ Executive function } \\
\hline \multirow{3}{*}{$\begin{array}{l}\text { DAS-II Working } \\
\text { Memory }\end{array}$} & $\leq 12$ yrs at birth & $2.5(1.5,4.1)$ & $2.2(1.4,3.6)$ & $2.6(1.5,4.6)$ & $2.5(1.5,4.2)$ \\
\hline & $>12,<16$ yrs at birth & $2.1(1.2,3.8)$ & $1.5(0.9,2.6)$ & $2.2(1.3,3.9)$ & $1.5(0.9,2.7)$ \\
\hline & Advanced after birth & - & - & $0.9(0.5,1.4)$ & $0.8(0.5,1.3)$ \\
\hline NEPSY-II Auditory & $\leq 12$ yrs at birth & $1.4(0.9,2.1)$ & $1.3(0.8,2.1)$ & $1.7(1.03,2.8)$ & $1.4(0.8,2.3)$ \\
\hline \multirow[t]{2}{*}{ Attention } & $>12,<16$ yrs at birth & $1.2(0.7,2.0)$ & $1.4(0.9,2.3)$ & $1.3(0.8,2.2)$ & $1.4(0.9,2.4)$ \\
\hline & Advanced after birth & - & - & $0.6(0.4,1.03)$ & $0.9(0.5,1.4)$ \\
\hline NEPSY-II Auditory & $\leq 12$ yrs at birth & $2.0(1.2,3.1)$ & $1.4(0.95,2.2)$ & $2.4(1.4,4.1)$ & $1.6(1.1,2.6)$ \\
\hline \multirow[t]{2}{*}{ Response Set } & $>12,<16$ yrs at birth & $1.3(0.8,2.3)$ & $0.8(0.5,1.3)$ & $1.4(0.8,2.5)$ & $0.9(0.5,1.4)$ \\
\hline & Advanced after birth & - & - & $0.6(0.4,1.1)$ & $0.8(0.5,1.3)$ \\
\hline NEPSY-II Inhibition & $\leq 12$ yrs at birth & $1.6(1.1,2.4)$ & $1.2(0.7,1.8)$ & $2.2(1.3,3.5)$ & $1.6(0.9,2.6)$ \\
\hline \multirow[t]{2}{*}{ Inhibition } & $>12,<16$ yrs at birth & $1.1(0.7,1.7)$ & $0.7(0.4,1.2)$ & $1.2(0.8,1.9)$ & $0.8(0.5,1.2)$ \\
\hline & Advanced after birth & - & - & $0.6(0.3,0.9)$ & $0.6(0.3,0.97)$ \\
\hline NEPSY-II Inhibition & $\leq 12 \mathrm{yrs}$ at birth & $2.6(1.6,4.1)$ & $2.0(1.3,3.0)$ & $3.3(1.9,5.6)$ & $1.9(1.2,3.1)$ \\
\hline \multirow[t]{2}{*}{ Switching } & $>12,<16$ yrs at birth & $1.9(1.2,3.2)$ & $1.6(0.98,2.5)$ & $2.1(1.2,3.5)$ & $1.6(0.96,2.5)$ \\
\hline & Advanced after birth & - & - & $0.6(0.3,1.01)$ & $1.0(0.6,1.7)$ \\
\hline NEPSY-II Animal & $\leq 12 \mathrm{yrs}$ at birth & $2.5(1.6,4.0)$ & $1.2(0.8,1.8)$ & $2.8(1.7,4.9)$ & $1.4(0.9,2.2)$ \\
\hline \multirow[t]{2}{*}{ Sorting } & $>12,<16$ yrs at birth & $2.4(1.4,4.0)$ & $1,6(0.99,2.5)$ & $2.5(1.5,4.2)$ & $1.6(1.03,2.6)$ \\
\hline & Advanced after birth & - & - & $0.8(0.5,1.3)$ & $0.7(0.4,1.2)$ \\
\hline \multicolumn{6}{|l|}{ Processing speed } \\
\hline NEPSY-II Inhibition & $\leq 12 \mathrm{yrs}$ at birth & $1.6(1.1,2.4)$ & $0.9(0.6,1.4)$ & $2.2(1.4,3.6)$ & $1.3(0.8,2.3)$ \\
\hline \multirow[t]{2}{*}{ Naming } & $>12,<16$ yrs at birth & $1.2(0.7,1.9)$ & $1.1(0.6,1.7)$ & $1.3(0.8,2.1)$ & $1.2(0.7,2.0)$ \\
\hline & Advanced after birth & - & - & $0.5(0.3,0.8)$ & $0.4(0.2,0.8)$ \\
\hline \multicolumn{6}{|l|}{ Visual perception } \\
\hline \multirow[t]{3}{*}{ NEPSY-II Arrows } & $\leq 12$ yrs at birth & $1.8(1.2,2.9)$ & $1.5(0.9,2.3)$ & $1.7(1.04,2.9)$ & $1.3(0.8,2.2)$ \\
\hline & $>12,<16$ yrs at birth & $1.4(0.8,2.3)$ & $1.6(0.98,2.5)$ & $1.4(0.8,2.3)$ & $1.5(0.9,2.4)$ \\
\hline & Advanced after birth & - & - & $1.1(0.7,1.8)$ & $1.3(0.8,2.2)$ \\
\hline NEPSY-II Geometric & $\leq 12$ years & $1.7(1.02,2.8)$ & $1.9(1.2,3.0)$ & $1.6(0.9,2.9)$ & $2.1(1.3,3.4)$ \\
\hline \multirow[t]{2}{*}{ Puzzles } & $>12,<16$ years & $1.4(0.8,2.4)$ & $1.3(0.8,2.1)$ & $1.4(0.8,2.4)$ & $1.3(0.8,2.2)$ \\
\hline & & - & - & $1.1(0.6,1.9)$ & $0.9(0.5,1.4)$ \\
\hline
\end{tabular}


Neurocognitive and Academic Achievement Test Scores by Maternal Eligibility for Public Health Insurance at Delivery (Supplementary Analysis)

Box-and-whisker plots show that the unadjusted medians and distributions of $Z$-scores for children of mothers eligible for public health insurance at delivery compared to children of mothers who were not (Supplementary Figure S1 online) were shifted downward on all measures. With adjustment for confounders (Supplementary Table S2 online), children born into low-income households showed a similar pattern of impairment as children of mothers with low educational attainment that were most pronounced on measures of verbal and nonverbal IQ, language, executive control, and academic achievement.

\section{Maternal Educational Advancement and Children's Neurocognitive and Academic Achievement Tests Scores at Age 10 years}

Children of mothers who advanced in education exhibited an overall tendency of reduced risk (ORs $<1$ ) of poor performance on almost all measures (Table 2). The largest reductions of risk tended to be on the same measures on which children of mothers of lower educational status at birth performed least well, including verbal IQ, language ability, executive control, and academic achievement, particularly in math. However, the only measures for which reduced risk was statistically significant were of inhibitory control and processing speed.

\section{DISCUSSION}

Extremely preterm children born into lower SES families had consistently poorer neurocognitive and academic outcomes at age 10 years than children from higher SES families, with adjustments for gestational age, maternal IQ, and other possible confounders. The most pronounced and consistent associations of lower SES, as measured by maternal education, were with verbal reasoning, language ability, executive functions, and academic skills, similar to those reported for low SES term-born community samples (16,29-32). Low household income at delivery (as measured by eligibility for public health, or Medicaid) also was associated with unfavorable neurocognitive outcomes.

These findings are similar to those recently reported for smaller cohorts of adults born very preterm $(10,11)$ but extend them in two ways. First, social disadvantage at birth has clear adverse effects, with adjustment for the severity of prematurity, on cognitive outcomes even among children born most preterm (i.e., at 23 to 27 weeks). Second, graded adverse effects of social disadvantage on neurocognitive and academic outcomes are already evident at school age in children born extremely preterm. Although other studies $(8,13)$ have detected evidence of graded associations between lower SES and poorer neurocognitive function as early as 5 years of age in children born very preterm, these associations were not adjusted for differences in gestational age. 

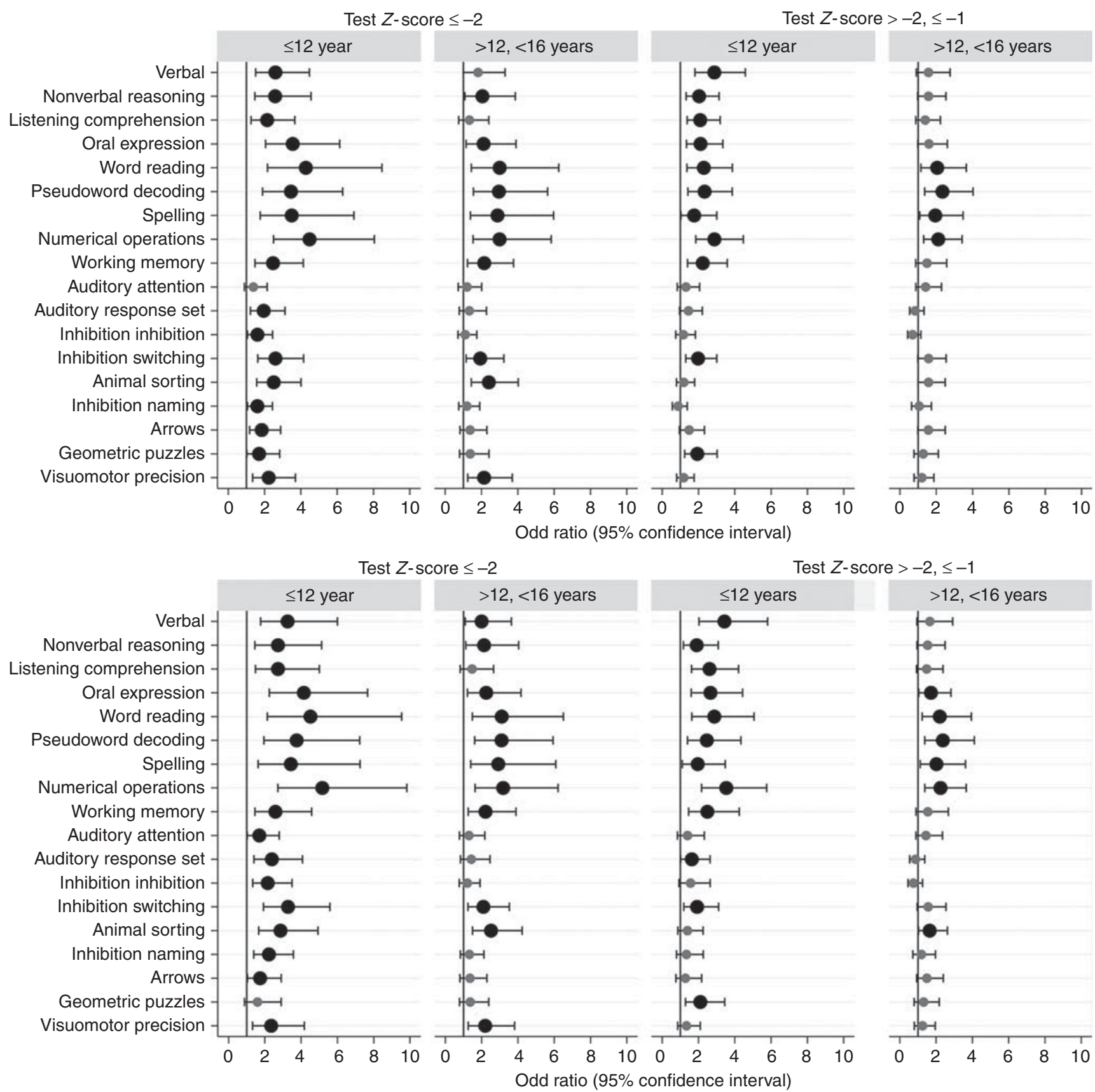

Figure 2. Top panel: Odds ratios (ORs) (95\% confidence intervals) of Z-scores $\leq-2$ or $>-2$ but $\leq-1$ for neurocognitive subtests associated with maternal education $\leq 12$ years and $>12$ but $<16$ years at the time the child was born. All models are adjusted for non-white race, maternal intelligence quotient (IQ) (Kaufman Brief Intelligence Test-2 (KBIT-2) Z-score $\leq-1)$, gestational age (23-24 and 35-26 weeks), and birth weight Z-score $<-1$; and all models account for the correlations between children from the same pregnancy. Bottom panel: ORs in the bottom panel are adjusted additionally for advance in maternal educational status between the birth of the child and the child's 10-year assessment. Large black dots indicate ORs significantly $>1.0$. Maximum $N=873$.

In addition, advancement in maternal education after delivery was associated with a reduced risk of unfavorable neurocognitive and academic outcomes, but for most outcomes this association was not statistically significant. Although in general population studies improvement in socioeconomic circumstances, most often measured by increases in household income, have been associated with better academic outcomes in middle childhood and beyond (33), the effects of improvement in socioeconomic circumstances, to our knowledge, have not been investigated with regard to neurocognitive and academic ability in children born very preterm. It is notable that in our sample mothers who advanced in educational attainment were more likely to have indicators of social disadvantage at the time of delivery (younger, non-white, eligible for Medicaid), with the one exception that they were more likely to be married. Further 
study of such patterns of association may help us to understand more precisely how social-environmental influences operate to affect the neurocognitive development of children born very preterm.

SES is a multidimensional construct that approximates an individual's overall position in society as related to education, occupation, and income. In this study, we used maternal education and, secondarily, eligibility for governmentprovided health care as indicators of SES. However, such indicators are widely recognized as proxies or markers for the myriad factors that actually mediate the effects of SES on a child's development. Adverse exposures and experiences associated with low SES include air pollution, tobacco smoke, household toxins, food insecurity, poor nutrition, inadequate parenting, and psychosocial stress related to social isolation, community violence, and racial discrimination (14). Among the biological mechanisms hypothesized to mediate the effects of social adversity on developmental outcomes of preterm infants are epigenetic modifications of gene expression in the mother as well as the child, but these processes are only beginning to be explored $(34,35)$.

Maternal education at the time of birth had a graded relationship with outcomes at age 10 years, with children whose mother had obtained some formal education beyond high school scoring intermediately between children whose mother had no formal education beyond high school and children whose mother had completed college. Thus, although we have focused on risk for poorer neurocognitive and academic outcomes, maternal education, as a proxy measure for SES, was also useful in identifying compensatory or protective factors, in that children born to mothers in the highest stratum of education obtained scores that were close to normative expectation on measures of IQ, language, and academic attainment (9).

Our finding that socioeconomic disadvantage at birth sets children born extremely preterm on a trajectory of significantly increased risk for poorer neurocognitive and academic outcomes, has important research, policy, and clinical implications. Research on more proximal factors that explain the mechanisms through which SES-related exposures lead to poorer cognitive outcomes is needed to understand, intervene upon, and potentially modify the deleterious effects of social disadvantage on prenatal and postnatal development. Such research can inform clinical care and public health policy initiatives that will reduce the most damaging exposures related to low SES. Otherwise, given the significant risk that it confers, family social disadvantage is an important factor for health-care providers to consider carefully in following children born extremely preterm (36).

Among the strengths of this study is the large sample size of prospectively followed extremely preterm infants and their families, and the diversity of their sociodemographic characteristics. In addition, we were able to assess associations between socioeconomic factors while adjusting for highquality estimates of gestational age and potential confounders such as fetal growth restriction and maternal IQ. As with all observational studies, we were limited in our ability to infer causation from association. Although there was a high degree of confluence among markers of socioeconomic disadvantage in our sample, our measures served only as proxies of a likely large array of pre- and postnatal environmental exposures that might mediate links between SES and neurocognitive outcomes of children born preterm. In addition, because this study did not include a term-born comparison group, we were unable to investigate whether socioecomic disadvantage might differentially affect outcomes of term-born and extremely preterm children. Finally, our findings may not apply to other countries that differ in the degree of socioeconomic disparity that exists in United States and in which differences in the availability of child care resources may moderate the effects of lower SES on children's neurocognitive outcomes.

In conclusion, among children born extremely preterm, socioeconomic disadvantage around the time of birth is associated with significantly poorer neurocognitive and academic outcomes at 10 years of age, independently of gestational age. Improvement in socioeconomic circumstances over the course of early childhood appears to have relatively limited effects on children's cognitive and academic outcomes.

\section{SUPPLEMENTARY MATERIAL}

Supplementary material is linked to the online version of the paper at http://www.nature.com/pr

\section{ACKNOWLEDGMENTS}

We express our gratitude to the children and their families who participated in this study. We also gratefully acknowledge the contributions of the ELGAN Study Investigators.

\section{MEMBERS OF THE ELGAN STUDY INVESTIGATORS}

The members of the ELGAN Study Investigators are as follows: Boston Children's Hospital, Boston MA-Janice Ware, Taryn Coster, Brandi Henson, Rachel Wilson, Kirsten McGhee, Patricia Lee, Aimee Asgarian, Anjali Sadhwani; Tufts Medical Center, Boston MA-Ellen Perrin, Emily Neger, Kathryn Mattern, Jenifer Walkowiak, Susan Barron-University of Massachusetts Medical School, Worcester MA-Jean Frazier, Lauren Venuti, Beth Powers, Ann Foley, Brian Dessureau, Molly Wood, Jill Damon-Minow; Yale University School of Medicine, New Haven, CT-Richard Ehrenkranz, Jennifer Benjamin, Elaine Romano, Kathy Tsatsanis, Katarzyna Chawarska, Sophy Kim, Susan Dieterich, Karen Bearrs; Wake Forest University Baptist Medical Center, Winston-Salem NC-T. Michael O'Shea, Nancy Peters, Patricia Brown, Emily Ansusinha, Ellen Waldrep, Jackie Friedman, Gail Hounshell, Debbie Allred-University Health Systems of Eastern Carolina, Greenville, NC -Stephen C. Engelke, Nancy Darden-Saad, Gary Stainback; North Carolina Children's Hospital, Chapel Hill, NC-Diane Warner, Janice Wereszczak, Janice Bernhardt, Joni McKeeman, Echo Meyer; Helen DeVos Children's Hospital, Grand Rapids, MI-Steve Pastyrnak, Wendy Burdo-Hartman, Julie Rathbun, Sarah Nota, Teri Crumb; Sparrow Hospital, Lansing, MlMadeleine Lenski, Deborah Weiland, Megan Lloyd; University of Chicago Medical Center, Chicago, IL-Scott Hunter, Michael Msall, Rugile Ramoskaite, Suzanne Wiggins, Krissy Washington, Ryan Martin, Barbara Prendergast, Megan Scott-William Beaumont Hospital, Royal Oak, MIJudith Klarr, Beth Kring, Jennifer DeRidder, Kelly Vogt.

\section{STATEMENT OF FINANCIAL SUPPORT}

This study was supported by the National Institute of Neurological Disorders and Stroke (5U01NS040069-09; 5U01NS04006-05), the National Institute of Child Health and Human Development (5P30HD018655-28), and the NIH ECHO Program (UG3OD023348-01). 
Disclosure: The authors declare no conflict of interest.

\section{REFERENCES}

1. Johnson S. Cognitive and behavioural outcomes following very preterm birth. Semin Fetal Neonatal Med 2007;12:363-73.

2. Anderson PJ. Neuropsychological outcomes of children born very preterm. Semin Fetal Neonatal Med 2014;19:90-6.

3. Johnson S, Fawke J, Hennessy E, et al. Neurodevelopmental disability through 11 years of age in children born before 26 weeks of gestation. Pediatrics 2009;124:e249-57.

4. Kerr-Wilson C, Mackay D, Smith G, Pell J. Meta-analysis of the association between preterm delivery and intelligence. Journal of Public Health 2012;34:209-16.

5. Joseph RM, O'Shea TM, Allred EN, et al. Neurocognitive and academic outcomes at age 10 years of extremely preterm newborns. Pediatrics 2016;137:e20154343.

6. Blumenshine P, Egerter S, Barclay CJ, Cubbin C, Braveman PA. Socioeconomic disparities in adverse birth outcomes: a systematic review. Am J Prev Med 2010;39:263-72.

7. Wong HS, Edwards P. Nature or nurture: a systematic review of the effect of socio-economic status on the developmental and cognitive outcomes of children born preterm. Matern Child Health J 2013;17:1689-700.

8. Manley BJ, Roberts RS, Doyle LW, et al. Caffeine for Apnea of Prematurity Trial I, Caffeine for Apnea of Prematurity CAPTISocial variables predict gains in cognitive scores across the preschool years in children with birth weights 500 to 1250 grams. J Pediatr 2015;166: 870-76 e871-872.

9. Schneider LA, Burns NR, Giles LC, et al. Cognitive abilities in preterm and term-born adolescents. J Pediatr 2014;165:170-7.

10. Ekeus C, Lindstrom K, Lindblad F, Rasmussen F, Hjern A. Preterm birth, social disadvantage, and cognitive competence in Swedish 18- to 19-yearold men. Pediatrics 2010;125:e67-73.

11. Eryigit Madzwamuse S, Baumann N, Jaekel J, Bartmann P, Wolke D. Neuro-cognitive performance of very preterm or very low birth weight adults at 26 years. J Child Psychol Psychiatry 2015;56:857-64.

12. Linsell L, Malouf R, Morris J, Kurinczuk JJ, Marlow N. Prognostic factors for poor cognitive development in children born very preterm or with very low birth weight: a systematic review. JAMA Pediatr 2015;169: 1162-72.

13. Potharst ES, Houtzager BA, van Sonderen L, et al. Prediction of cognitive abilities at the age of 5 years using developmental follow-up assessments at the age of 2 and 3 years in very preterm children. Dev Med Child Neurol 2012;54:240-6.

14. Lorch SA, Enlow E. The role of social determinants in explaining racial/ ethnic disparities in perinatal outcomes. Pediatr Res 2016;79:141-7.

15. Leviton A, Paneth N, Reuss ML, et al. Maternal infection, fetal inflammatory response, and brain damage in very low birth weight infants. Pediatric Res 1999;46:566-75.

16. Noble KG, Houston SM, Brito NH, et al. Family income, parental education and brain structure in children and adolescents. Nat Neurosci 2015;18:773-8.
17. Wolke D. Psychological development of prematurely born children. Arch Dis Child 1998;78:567-70.

18. Bendersky M, Lewis M. Environmental risk, biological risk, and developmental outcome. Dev Psychol 1994;30:484.

19. Doyle LW, Cheong JL, Burnett A, Roberts G, Lee KJ, Anderson PJ. Victorian Infant Collaborative Study G Biological and social influences on outcomes of extreme-preterm/low-birth weight adolescents. Pediatrics 2015;136:e1513-20.

20. Lieberman E, Ryan KJ, Monson RR, Schoenbaum SC. Risk factors accounting for racial differences in the rate of premature birth. $\mathrm{N}$ Engl J Med 1987;317:743-8.

21. Trzaskowski M, Harlaar N, Arden R, et al. Genetic influence on family socioeconomic status and children's intelligence. Intelligence 2014;42: 83-8.

22. O'Shea TM, Allred EN, Dammann O, et al. The ELGAN study of the brain and related disorders in extremely low gestational age newborns. Early Hum Dev 2009;85:719-25.

23. Kaufman AS, Kaufman NL. Kaufman Brief Intelligence Test-2 (KBIT-2). San Antonio, TX: Pearson Education.

24. Palisano RJ, Hanna SE, Rosenbaum PL, et al. Validation of a model of gross motor function for children with cerebral palsy. Phys Ther 2000;80: 974-85.

25. Elliott CD. Differential Ability Scales. San Antonio, TX: Pearson Education, 2007.

26. Carrow-Woolfolk E. Oral and Written Language Scales (OWLS). San Antonio, TX: Pearson Education, 1995.

27. Korkman M, Kirk U, Kemp S. NEPSY-II: Clinical and Interpretive Manual. San Antonio, TX: Pearson Education, 2007.

28. Wechsler D. The Wechsler Individual Achievement Test-III. San Antonio, TX: Pearson Assessment, 2009.

29. Farah MJ, Shera DM, Savage JH, et al. Childhood poverty: specific associations with neurocognitive development. Brain Res 2006;1110: $166-74$.

30. Noble KG, Norman MF, Farah MJ. Neurocognitive correlates of socioeconomic status in kindergarten children. Dev Sci 2005;8:74-87.

31. Sirin SR. Socioeconomic status and academic achievement: a metaanalytic review of research. Rev Educ Res 2005;75:417-53.

32. Ardila A, Rosselli M, Matute E, Guajardo S. The influence of the parents' educational level on the development of executive functions. Dev Neuropsychol 2005;28:539-60.

33. Duncan GJ, Magnuson K, Votruba-Drzal E. Moving beyond correlations in assessing the consequences of poverty. Annu Rev Psychol 2017;68: 413-34.

34. Burris $\mathrm{HH}$, Baccarelli AA, Wright RO, Wright RJ. Epigenetics: linking social and environmental exposures to preterm birth. Pediatr Res 2016;79: $136-40$.

35. Rubin LP. Maternal and pediatric health and disease: integrating biopsychosocial models and epigenetics. Pediatr Res 2016;79:127-35.

36. Garg A, Boynton-Jarrett R, Dworkin PH. Avoiding the unintended consequences of screening for social determinants of health. JAMA 2016;316:813-4. 